\title{
Boštjan Kiauta
}

\section{Prva zoografija slovenske favne: komentarji Pietra Andrea Matthiolija $\mathrm{k}$ Dioskoridovemu farmakološkemu

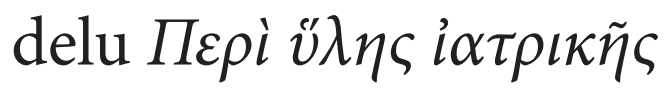

V okviru renesančnega oživljanja antike je monumentalno delo Pietra Andrea Matthiolija (tudi Matthiolus) Commentarii in libros sex Pedacii Dioscoridis [...] klasičen primer obujanja starogrškega duha, ki ga oplemenituje in znanstveno bistveno nadgrajuje. Delo je prvič izšlo leta $1544 \mathrm{v}$ italijanščini, brez slik, $1554 \mathrm{v}$ latinščini, bogato ilustrirano, nato pa še v več deset latinskih izdajah in prevodih $\mathrm{v}$ francoščino, nemščino in češčino in je nekaj stoletij služilo kot osnova farmakoloških priročnikov.

Grški farmakolog Pedanius Dioskorides iz kraja Anazarb v Kilikiji (grško: Anazarba, latinsko: Anazarbus), danes Turčija (rojen okoli 40, umrl okoli 90 n. št.) je bil vojaški zdravnik v času cesarjev Klavdija in Nerona. Njegovo

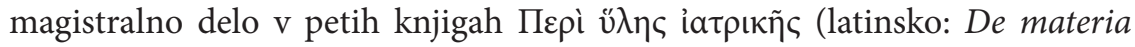
medica) je nastalo okoli leta 77 n. št. in je slovelo kot vodilni farmakološki priročnik vse do renesanse. Avtor velja za največjega grškega botanika po Teofrastu. Grški rokopis je bil preveden v vsaj sedem jezikov, avtoritativna angleška izdaja pa je izšla leta 1934 (Encyclopaedia Britannica [Micropaedia] 3 [1979]: 563). Glej tudi Kudlien, »Dioskurides«

Ker je Matthioli, italijanski zdravnik in naravoslovec (rojen v Sieni 1501, umrl v Trentu 1577), v letih 1541-1555 služboval kot deželni zdravnik v Gorici in je v tistem obdobju mnogo potoval po Kranjskem in Istri, je mogel vključiti v svoje Komentarje številne slovenske alpske in kraške rastlinske in živalske vrste. Delo je razumeti kot osnovo in hkrati vrhunec renesančnih raziskav flore na sedanjem slovenskem ozemlju in kot prvo opisno zoologijo (zoografijo) dela slovenske favne. Slovenski botaniki so o njem večkrat razpravljali (Petkovšek, 
»Po sledovih prvih floristov«, »Ob štiristoletnici florističnih prizadevanj«, Scopoli, njegovo življenjsko delo; Wraber \& Prijatelj, »Mattioli«), slovenskim zoologom pa je ostalo domala neznano in nanj niso opozarjali (vendar glej Sket et al., Živalstvo Slovenije). Grošelj, »Prirodoznanska prizadevanja«, celo trdi, da se zoografija Slovencev ni dotaknila, in Matthiolija ne omenja, čeprav je izvod izdaje iz leta 1569 (iz knjižnice nekdanjega ljubljanskega Liceja) na voljo v Narodni in univerzitetni knjižnici v Ljubljani. To je deloma razumljivo, ker iz naslova dejanska vsebina dela ni razvidna. Izvod ni digitaliziran, njegova naslovnica pa je bila nekajkrat reproducirana v slovenskem tisku.

V Sloveniji velja delo kot knjižna rariteta prve vrste, dejansko pa ni redko; številne izdaje se nahajajo v mnogih uglednejših knjižnicah po Evropi in v svetu in se pojavljajo večkrat tudi na knjižnem trgu, kjer ne dosegajo eksorbitantnih cen. Tudi W. Junk ga v delu Rara historico-naturalis et mathematica (Amsterdam: Asher, 1900-1936) ne omenja med knjižnimi redkostmi.

Pred seboj imamo digitaliziran izvod latinske izdaje iz leta 1565, po originalu v Smithsonian Institution Libraries, Washington: P. A. Matthioli, Commentarii in sex libros Pedacii Dioscoridis Anazarbei de Medica materia, iam denuo ab ipso autore recogniti, et locis plus mille aucti [...]. Venetiis: Officina Valgrissiana, 1565. clxxvi+1459 str.

Knjigo sestavlja 7 delov. Uvodu (s posvetilom nadvojvodoma Ferdinandu in Karlu, predgovorom, indeksi obdelanih rastlinskih in živalskih vrst, ilustracij in drugega itd.; 176 neoštevilčenih strani) sledi 6 oddelkov, imenovanih liber/knjiga: (1) str. 1-294, (2) 295-636, (3) 637-942, (4) 943-1312, (5) 1313-1393 in (6) 1394-1459. Večina živali je obdelana v 2. »knjigi«, nekaj tudi drugod. Vrstni red opisov sledi v glavnem abecednemu redu začetnic uporabljenih živalskih imen.

Obdelane so le živali, ki so se v evropski farmakologiji uporabljale za pripravo zdravil. Tako npr. kačjih pastirjev, za katere se uporablja v renesančni latinščini izraz perlae, evropska materia medica ne pozna, zato manjkajo, čeprav so jih v farmakologiji vzhodne, jugovzhodne in srednje Azije uporabljali še v polpreteklem času in jih pozna že (indijska) ajurvedska farmakologija. Uporabo kačjih pastirjev v kitajski tradicionalni medicini obravnavajo npr. Yang, Investigation on the Insects (številne vrste), Read, Chinese materia medica (zdravilni učinki) in $\mathrm{Hu}$, An Enumeration of Chinese materia medica (samo ličinke), za tradicionalno tibetansko farmakologijo pa Kiauta, »Further Annotations « (z bibliografskimi referencami in opombami).

Podobno kot herbariji izvirajo tudi najstarejše zasebne in muzejske entomološke zbirke v Evropi iz renesanse. Ena prvih in največjih je bila tista, ki jo je zbral Ulysse Aldrovandi (Bologna; 1522-1605). Vsaj do leta 1773 je bila v hrambi avtorjeve družine (Hagen, Bibliotheca entomologica, 7), njena kasnejša usoda pa je neznana. Na obseg zbirke sklepamo iz avtorjevega objavljenega gradiva, ki temelji na njej: De animalibus insectis libri septem. In quibus omnia illa Animalia accuratissime describuntur, eorum icones ad vivum ob oculos 
ponuntur, tandemque etiam natura mores ac proprietates ita declarantur, ut quidquid de dici queat, facile inde innotescat. Ilis adjunctus est Index geminus capitum et verborum copiossimus (prva izdaja 1602).

Velepomembno renesančno gradivo je zbral tudi Švicar Conrad Gesner (1516-1565). O usodi le-tega in njegovi posmrtni objavi glej Kiauta, »An outline of the history of odonatology«.

Z gotovostjo je imel tudi Matthioli obsežno zbirko, v kateri je bilo mnogo živali s slovenskih najdiščc, o njeni usodi pa ne vemo ničesar.

J. W. Valvasor je imel v svoji knjižnici na Bogenšperku (sedaj v Zagrebu) nemško (1590) in latinsko (1674) izdajo Matthiolijevih del (Gostiša, Bibliotheca Valvasoriana, 502), toda v 3. knjigi svoje Slave (1689) omenja le njegov Herbarium.

Presenetljivo je, da je tudi N. Poda v delu Insecta musei graecensis, quae in ordines, genera et specis juxta Systema Naturae Caroli Linnaei digessit [...] (1761) Matthiolija prezrl.

Nasprotno se je Ioannes Antonius Scopoli (1723-1788) v svojih delih nanj močno opiral, vendar se je predvsem o njegovem botaničnem delu pogosto izražal negativno, kritično, mestoma domala žaljivo, in ni priznaval Matthiolijeve prioritete $\mathrm{v}$ floristiki slovenskega prostora. Ker je slednji deloval skoraj dve stoletji pred Scopolijem, tu ne gre za medsebojno »konkurenco « raziskovalcev istega področja, temveč morda le za neke vrste primitivno Scopolijevo "nevoščljivost« do svojega predhodnika (glej Petkovšek, J. A. Scopoli).

V svoji Entomologiji navaja Scopoli Matthiolija, brez komentarja, pri 12 vrstah žuželk in drugih členonožcev. V Scopolijevi nomenklaturi in vrstnem redu so to (strani citatov v Entomologiji so v oklepajih): Cicada plebeja (117), Cimex lectularius (121), Scorpio europaeus (404), Cancer maenas (405), Cancer pagurus (406), Cancer maja (406), Cancer gammarus (407), Cancer astacus (407), Cancer squilla (408), Cancer bernardus (408), Oniscus asellus (414) in Scolopendra marina (?) (417).

Večina raziskovalcev zgodovine entomologije omenja Dioskorida in Matthiolija le bežno, npr. M. Beier v »The early naturalists and anatomists during the renaissance and seventeenth century" (1973) in G. Morge v "Entomology in the western world in antiquity and in medieval times" (1973), oba v R. F. Smith in sodelavci (ur.), History of entomology (Palo Alto: Annual Reviews, 1973), svetla izjema pa je Bodenheimer (1928-1929), ki je prikazal razne aspekte Dioskoridovega in Matthiolijevega entomološkega znanja, jih kratko komentiral in izpostavil iz neke neimenovane, očividno italijanske izdaje (Bodenheimer, Materialien, 2:332) čebele, nekaj vrst hroščev (Buprestis, Cantharis), ščurke, škržate, gosenice (predvsem belinov in borovega prelca), kobilice in posteljno stenico.

Matthiolijev indeks k tekstu obsega 44 strani in vsebuje blizu 5000 gesel. Njegov seznam slik obsega 6 strani z okoli 1000 gesli in je urejen po »knjigah «. Okoli $90 \%$ od teh so rastline, ostalo odpade na živali in rudnine. Rastlinsko 
gradivo so botaniki taksonomsko identificirali in ugotovili nekaj nad 1100 taksonov cvetnic (Petkovšek, J. A. Scopoli). Iz Matthiolijeve primerjave med Dioskoridovim in svojim gradivom je razvidno, da je Matthioli k Dioskoridovemu originalnemu delu priključil opise blizu 300 dodatnih rastlinskih taksonov (Wraber in Prijatelj, »Mattioli«).

Živalsko gradivo, predstavljeno v Komentarjih, še ni prevedeno v moderno taksonomsko nomenklaturo. Za strokovnjake posameznih živalskih skupin bo to zapleteno in skrajno zamudno delo, ki bo šele omogočilo pravilno ocenitev Matthiolijeve predstavitve slovenskega živalskega sveta pred malo manj kot pol tisočletja. ${ }^{1}$

\section{BIBLIOGR AFIJA}

Bodenheimer, F. S. Materialien zur Geschichte der Entomologie bis Linné. 2 zvezka. Berlin: Junk, 1928, 1929.

Gostiša, L., ur. Bibliotheca Valvasoriana: katalog knjižnice Janeza Vajkarda Valvasorja. Ljubljana: Valvasorjev odbor pri Slovenski akademiji znanosti in umetnosti, in Zagreb: Nacionalna i sveučilišna knjižnica, 1995.

Grošelj, P. »Prirodoznanska prizadevanja med Slovenci.« Proteus 6 (1940): 113-121, 165-173.

Hagen, H. A. Bibliotheca entomologica. 2 zvezka. New York: Hafner, 1960 (ponatis prve izdaje iz 1862).

Hu, S.-y. An Enumeration of Chinese materia medica. Hong Kong: Chinese University Press, 1980.

Kiauta, B. »An outline of the history of odonatology in Switzerland, with an annotated bibliography on the Swiss odonate fauna." Odonatologica 7.3 (1978): 191-222.

Kiauta, M. A. J. E. »Further annotations on the Tibetan expressions for 'dragonfly'.« Odonatologica 6.2 (1977): 69-76.

Kudlien, F. »Dioskurides, 5. Pedanius." V: Der kleine Pauly. Lexicon der Antike, ur. K. Ziegler in W. Sontheimer, 2. zv. (Dicta Catonis - Iuno), stolpec 91. München: Deutscher Taschenbuch Verlag, 1979.

Petkovšek, V. »Po sledovih prvih floristov v naših gorah.« Planinski vestnik 66 (1966): 297-306.

Petkovšek, V. »Ob štiristoletnici florističnih prizadevanj predhodnikov I.A. Scopolija.« Biološki vestnik 15 (1967): 51-62.

Petkovšek, V. J. A. Scopoli, njegovo življenjsko delo v slovenskem prostoru. Razprave SAZU, Razred za prirodoslovne vede 20.2. Ljubljana: SAZU, 1977.

Poda, N. Insecta musei graecensis, quae in ordines, genera et specis juxta Systema Naturae Caroli Linnaei digessit [...]. Graecii: Typis Haeredum Widmanstadii, 1761.

Read, B. E. Chinese materia medica. Insect drugs [...]. Chinese Medicine Series 2. Taipei: Southern Materials Center, 1977.

Scopoli, I. A. Entomologia carniolica. Exhibens insecta Carnioliae indigena et distributa in ordines, genera, species, varietates methodo Linnaeana. Vindobonae: Trattener, 1763 .

1 Akademiku prof. dr. Matiji Gogala (SAZU, Ljubljana) sem hvaležen za posredovanje elektronske kopije Matthiolijevega dela, dr. Nadi Grošelj (Univerza v Ljubljani) pa za pomoč z bibliografskimi informacijami o Dioskoridu in za pomoč glede Valvasorja. 
Sket, B., M. Gogala in V. Kuštor. Živalstvo Slovenije. Ljubljana: Tehniška založba Slovenije, 2003.

Wraber, T. in A. Prijatelj. "Mattioli, Pietro Andrea.« Enciklopedija Slovenije 7 (1993): 25.

Yang, T.-h. Investigation on the Insects Used for Medicine in Chinese Pharmacology. Doktorska disertacija. Taipei: University of Taipei, 1976. 
Summary

THE EARLIEST ZOOGRAPHY OF

SLOVENIAN FAUNA: COMMENTS BY PIETRO

ANDREA MATTHIOLI ON DIOSCORIDES'

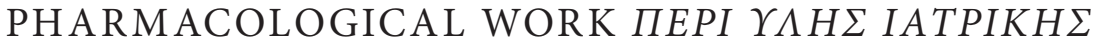

The paper presents the monumental work of P. A. Matthioli, Commentarii in libros sex Pedacii Dioskoridis Anazarbei de Medica materia [...] (clxxvi+1459 pp.; Venetiis: Officina Valgrissiana), published first (1544) in Italian and subsequently in several dozens of Latin, French, German and Czech editions. Dioscorides' original account of pharmacologically applicable plants and animals was expanded by Matthioli, who resided during 1541-1555 in Gorica/Gorizia (located on the present-day Slovenia/Italy border), with several hundred species from the Slovenian territories of Carniola and Istria, including numerous vertebrates, insects, other arthropods and some amerians, mostly with illustrations and descriptions. Thus the work represents the first zoography of Slovenian fauna, based on the extent to which the species were used in the preparation of medicaments.

Surprisingly, J. W. Valvasor (Die Ehre des Hertzogthums Crain, Nürnberg: Endter, 1689) and N. Poda (Insecta musei graecensis, Graecii: Typis Haeredum Widmanstadii, 1761) make no reference to Matthioli's work. On the other hand, I. A. Scopoli (Entomologia carniolica, Vindobonae: Trattener, 1763) lists it with 12 insect and other arthropod species, viz. (in his sequence and nomenclature): Cicada plebeja, Cimex lectularius, Scorpio europaeus, Cancer maenas, Cancer pagurus, Cancer maja, Cancer gammarus, Cancer astacus, Cancer squilla, Cancer bernardus, Oniscus asellus and Scolopendra marina (?).

While botanists have identified ca 300 (largely) Slovenian phanerogame taxa (cf. T. Wraber \& A. Prijatelj, Enciklopedija Slovenije, 1993), the translation of animal appellations into modern taxonomic nomenclature is still wanting, therefore a final assessment of the faunistic importance of Matthioli's work is not feasible as yet. 